\title{
SCIDic
}

\author{
International Journal of Dentistry and Oral Science (IJDOS) \\ ISSN: 2377-8075
}

\section{Palatal Rugae Patterns Among a Sudanese Population Sample}

Research Article

Khalid $\mathrm{K}^{1^{*}}$, Phillips $\mathrm{VM}^{2}$

${ }^{1}$ Forensic Dentistry Department, Faculty of Dentistry, University of Science and Technology, Omdurman, Sudan.

${ }^{2}$ Oral and Maxillofacial Pathology, UWC Dental Faculty, TYGERBERG, South Africa.

\section{Abstract}

Palatal rugae patterns can have a significant role in forensic identification when it is difficult to use the normal identification methods. This study aimed to identify the morphological patterns of palatal rugae in a sample of Sudanese dental students attending the University of Science and Technology - Omdurman - Sudan. Maxillary impression models obtained from 100 subjects (50 males and 50 females). The data were assessed based on the Thomas and Kotze classification (1983). Results showed that the prevalence of the palatal rugae numbers was significantly more in females than in males. On the right side of the palate, the straight type of rugae was significantly predominant in females than in males whilst the wavy shape was more in males than in females. On the left side of the palate, the curved type of rugae was significantly more presented in males than in females whilst the diverging unification type was more in females than in males. The predominant rugae shapes in both males and females were straight, wavy and least was the circular. This study showed individuality of palatal rugae that can be used in forensic identification, and possibly distinction between males and females.

Keywords: Palatal Rugae; Morphological Patterns; Dental Identification; Forensic Dentistry.

\section{Introduction}

One of the most challenging processes in forensic science is forensic identification of the deceased [1]. Forensic identification has a major role socially and legally regarding the rights of the dead persons and their families [2]. Palatal rugae, also called pliace platinus transverse or rugae platinus, are ridges resulted from symmetrical and irregular mucosal folds of tissue made from the lateral membrane of the incisive papilla, and located in the alveolar third of the palate [3]. Palatal rugae might be regarded as an alternative comparative method for identification. The importance of palatal rugae in forensic identification had been shown due to their morphological stability during life. Studies have showed that palatal rugae were an alternative method of forensic identification when the routine methods failed [3, 4]. Moreover, palatal rugae pattern or shape remained stable and saved by the lips, the buccal pad of fat and the teeth which protect them during the challenging situations of mass disasters and incinerations [5].

The rugae were not symmetrical in number or distribution when the right and the left side of the palate were compared. Indera et al showed each individual had a different rugal pattern regarding its number or distribution [6].

The aim of this study was to identify the different morphological rugal patterns in a sample of adult males and females of Sudanese origin for identification purposes.

\section{Materials and Methods}

This was a cross-sectional study conducted among the students of the faculty of dentistry, University of Science and Technology in Sudan. A total of 100 participants, 50 males and 50 females of age groups $21-23$ year with mean age $21.66+0.61$ year were selected for the study. Participants with history of extraction, orthodontic treatment, congenital malformation or defects of the palate or with previous orthoganthic surgery were excluded from the study. Participants signed an informed consent prior to impression taking. The mouth of the participant was rinsed with chlorohexidine $(0.12 \%)$ mouth wash then an alginate impression

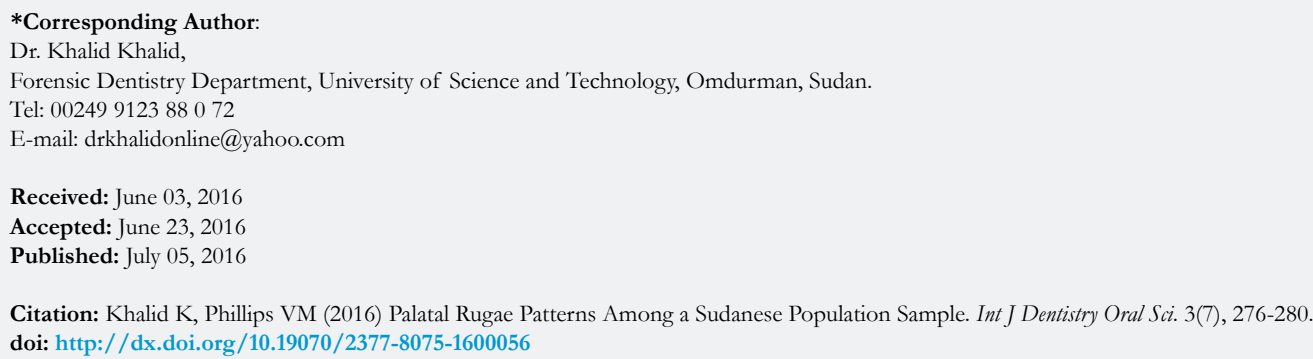

Copyright: Khalid $\mathbf{K}^{\circ}$ 2016. This is an open-access article distributed under the terms of the Creative Commons Attribution License, which permits unrestricted use, distribution and reproduction in any medium, provided the original author and source are credited. 
of the upper jaw of the patient was taken, and then casted by dental stone (type IV). The rugae pattern was analyzed using the Thomas and Kotze classification (1983). Of all the other palatine rugae classifications, it was the easiest, most practical and standardize [13]. The Thomas and Kotze classification categorized the rugae according to their length into primary (more than $5 \mathrm{~mm}$ ), secondary $(3-5 \mathrm{~mm})$ and fragmentary $(2-3 \mathrm{~mm})$. Rugae less than $2 \mathrm{~mm}$ were disregarded. The prevalence of rugae was measured by counting them per palate. Thomas and Kotze classified the rugae into six major types according to their shape which included straight, curved, wavy, circular, diverging unification and converging unification (Figure 1, Figure 2). The rugal shape that did not match with the Thomas and Kotze classification were recorded as unspecified. The Independent- $t$-Test was used to assess the significant difference of the total number of each type of palatal rugae between males and females. Descriptive statistical analysis was applied using SPSS to obtain the means, standard deviations, from the data of each category.

This research was approved by the Research and Ethics Committee of the University of the Western Cape, South Africa and the Research and Ethics Committee of the Faculty of Dentistry - University of Science and Technology - Sudan.

\section{Results}

The mean of the rugae total number was 10.27 for a participant. The total number of the primary type of palatal rugae had the largest mean (9.15) comparing with the secondary (1.07) and fragmentary (0.05) ones. (Table 1)

Statistical analysis showed significant difference in the number of palatal rugae between Sudanese males and females. The total number of the palatal rugae in females was significantly more than in males. Similarly, the total number of the palatal rugae in the right side of the palate was statistically significant in females more than males. (Table 2)

The total number of primary rugae in females was significantly more common than in males. The primary palatal rugae were the most common in males and females, followed by secondary rugae, then fragmentary rugae. (Table 3)

The total number of straight rugae on the right side of the palate was significantly more common in females than in males whilst the wavy shape was significantly more common in males than in females. (Table 4)

Figure 1. The rugal patterns outlined in pencil showing different types of palatal rugae shapes (A): (1) diverging (2) curved (3) straight (4) wavy.

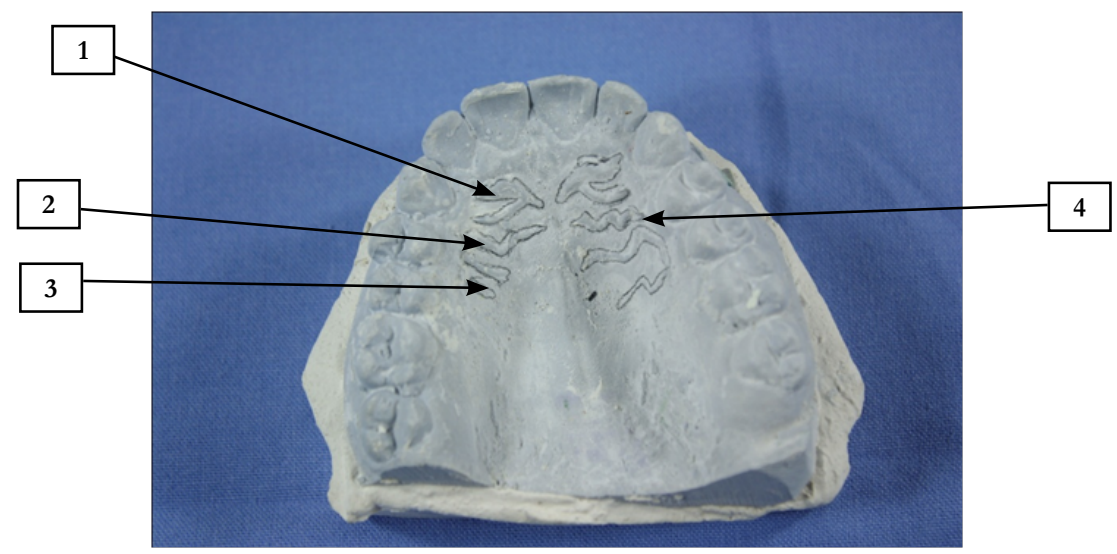

Figure 2. The rugal patterns outlined in pencil showing different types of palatal rugae shapes (B): (1) converging (2) circular.

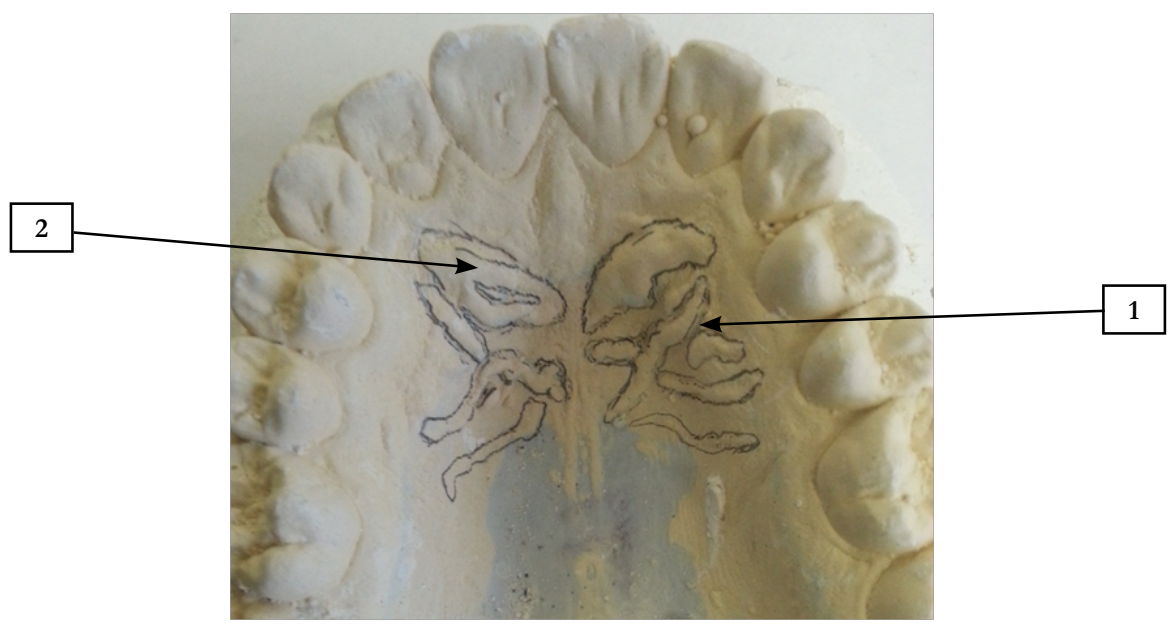


Table 1. Descriptive analysis of the total number of rugae.

\begin{tabular}{|c|c|c|c|}
\hline & $\mathbf{N}$ & Mean & SD \\
\hline Prevalence & 100 & 10.27 & 1.74 \\
\hline Primary & 100 & 9.15 & 1.35 \\
\hline Secondary & 100 & 1.07 & 1.25 \\
\hline Fragmentary & 100 & 0.05 & 0.22 \\
\hline Straight & 100 & 3.01 & 2.02 \\
\hline Circular & 100 & 0.16 & 0.39 \\
\hline Curved & 100 & 2.17 & 1.66 \\
\hline Wavy & 100 & 2.84 & 1.66 \\
\hline Diverging & 100 & 1.45 & 1.22 \\
\hline Converging & 100 & 0.53 & 0.76 \\
\hline Unspecified & 100 & 0.11 & 0.39 \\
\hline
\end{tabular}

Table 2. Distribution of palatal rugae numbers in males and females.

\begin{tabular}{|c|c|c|c|c|c|c|}
\hline & Gender & N & Rugae number & Mean & SD & P-value \\
\hline \multirow{2}{*}{ Prevalence (Right) } & Male & 50 & 238 & 4.76 & 0.8 & \multirow{2}{*}{$0.017^{*}$} \\
\cline { 2 - 7 } & Female & 50 & 262 & 5.24 & 1.15 & \\
\hline \multirow{2}{*}{ Prevalence (Left) } & Male & 50 & 256 & 5.12 & 1.32 & \multirow{3}{*}{0.254} \\
\cline { 2 - 6 } & Female & 50 & 271 & 5.42 & 1.32 & \\
\hline \multirow{2}{*}{ Prevalence (Total) } & Male & 50 & 494 & 9.88 & 1.29 & \multirow{2}{*}{$0.024^{*}$} \\
\cline { 2 - 6 } & Female & 50 & 533 & 10.66 & 1.81 & \\
\hline \multicolumn{7}{|c|}{ P-value is significant } \\
\end{tabular}

Table 3. Distribution of rugae length in males and females.

\begin{tabular}{|c|c|c|c|c|c|c|}
\hline & Gender & $\mathbf{N}$ & Rugae number & Mean & SD & P-value \\
\hline \multirow{3}{*}{ Primary } & Male & 50 & 442 & 8.84 & 1.23 & \multirow{2}{*}{$0.021^{*}$} \\
\cline { 2 - 6 } & Female & 50 & 473 & 9.46 & 1.4 & \\
\hline \multirow{2}{*}{ Secondary } & Male & 50 & 48 & 0.96 & 1.21 & \multirow{2}{*}{0.384} \\
\cline { 2 - 6 } & Female & 50 & 59 & 1.18 & 1.3 & \\
\hline Fragmentary & Male & 50 & 3 & 0.06 & 0.24 & \multirow{2}{*}{0.65} \\
\cline { 2 - 5 } & Female & 50 & 2 & 0.04 & 0.19 & \\
\hline \multicolumn{7}{|c|}{${ }^{*}$ P-value is significant } \\
\end{tabular}

On the left side of the palate, the curved shape of rugae showed statistical significance between the total number and gender. It was more prevalent in males than females. The total number of diverging unification shape of rugae were significantly more in females than in males on the left side of the palate. (Table 5)

The distribution of number of rugae shapes in both males and females were seen as straight, wavy, curved, diverging unification, converging unification, circular, and the unspecified respectively. The total number of straight rugae was significantly more common in females than in males, as well as circular rugae and diverging rugae. Converging rugae were common in females than in males while the curved rugae were more common in males than in females. (Table 6)

\section{Discussion}

In this study there were 11 individuals who showed rugae did not comply with the Thomas and Kotze classification; thus were recorded as unspecified. They did not appear in the Thomas and Kotze classification or any other published classification. These kinds of rugae should be investigated and classified if possible. It can be suggested that the Thomas and Kotze classification (1983) is applicable to the population sample of Sudanese origin.

The mean total number of the palatal rugae in this study was statistically significant and found to be greater in females than in males. This was consistent with the Nigerian and Indians studies [7-9]. In contrast, these findings were not similar to Jordanian and Japanese studies $[10,11]$.

Moreover, the total number of primary rugae in females in this study was significant greater in females than in males. These results agreed with Gondivkar et al., who found similar results in their western Indian population sample [12]. The length of rugae may suggested to be consider in gender differentiation in Sudanese samples. 
Table 4. Distribution of different rugae shapes on the right side of the palate in males and females.

\begin{tabular}{|c|c|c|c|c|c|c|}
\hline & Gender & $\mathbf{N}$ & Rugae number & Mean & SD & P-value \\
\hline \multirow{2}{*}{ Straight } & Male & 50 & 58 & 1.16 & 0.95 & \multirow{2}{*}{$0.012^{*}$} \\
\hline & Female & 50 & 87 & 1.74 & 1.29 & \\
\hline \multirow{2}{*}{ Circular } & Male & 50 & 3 & 0.06 & 0.24 & \multirow{2}{*}{0.186} \\
\hline & Female & 50 & 7 & 0.14 & 0.35 & \\
\hline \multirow{2}{*}{ Curved } & Male & 50 & 46 & 0.92 & 1.05 & \multirow{2}{*}{0.774} \\
\hline & Female & 50 & 49 & 0.98 & 1.04 & \\
\hline \multirow{2}{*}{ Wavy } & Male & 50 & 90 & 1.8 & 1.14 & \multirow{2}{*}{$0.003^{*}$} \\
\hline & Female & 50 & 56 & 1.12 & 1.06 & \\
\hline \multirow{2}{*}{ Diverging unification } & Male & 50 & 29 & 0.58 & 0.7 & \multirow{2}{*}{0.068} \\
\hline & Female & 50 & 43 & 0.86 & 0.81 & \\
\hline \multirow{2}{*}{ Converging unification } & Male & 50 & 12 & 0.24 & 0.48 & \multirow{2}{*}{0.234} \\
\hline & Female & 50 & 18 & 0.36 & 0.52 & \\
\hline \multirow{2}{*}{ Unspecified } & Male & 50 & 0 & 0 & 0 & \multirow{2}{*}{0.156} \\
\hline & Female & 50 & 2 & 0.04 & 0.19 & \\
\hline
\end{tabular}

${ }^{*} \mathrm{P}$-value is significant

Table 5. Distribution of different rugae shapes on the left side of the palate in males and females.

\begin{tabular}{|c|c|c|c|c|c|c|}
\hline & Gender & $\mathbf{N}$ & Rugae number & Mean & SD & P-value \\
\hline \multirow{2}{*}{ Straight } & Male & 50 & 68 & 1.36 & 1.19 & \multirow{3}{*}{0.146} \\
\cline { 2 - 7 } & Female & 50 & 88 & 1.76 & 1.52 & \\
\hline \multirow{2}{*}{ Circular } & Male & 50 & 1 & 0.02 & 0.14 & \multirow{2}{*}{0.095} \\
\cline { 2 - 7 } & Female & 50 & 5 & 0.1 & 0.3 & \\
\hline \multirow{2}{*}{ Curved } & Male & 50 & 77 & 1.54 & 1.18 & \multirow{2}{*}{$0.004^{*}$} \\
\cline { 2 - 7 } & Female & 50 & 45 & 0.9 & 0.99 & \\
\hline \multirow{2}{*}{ Diverging unification } & Male & 50 & 69 & 1.38 & 1.12 & \multirow{2}{*}{1} \\
\cline { 2 - 7 } & Female & 50 & 69 & 1.38 & 0.9 & \\
\cline { 2 - 7 } & Male & 50 & 27 & 0.54 & 0.58 & \multirow{2}{*}{$0.008^{*}$} \\
\hline \multirow{2}{*}{ Converging unification } & Male & 50 & 8 & 0.16 & 0.37 & \multirow{2}{*}{0.136} \\
\cline { 2 - 6 } & Female & 50 & 15 & 0.3 & 0.54 & \\
\hline \multirow{2}{*}{ Unspecified } & Male & 50 & 6 & 0.12 & 0.48 & \multirow{2}{*}{0.432} \\
\cline { 2 - 6 } & Female & 50 & 3 & 0.06 & 0.24 & \\
\hline
\end{tabular}

* P-value is significant

This study revealed that the most common types of rugae in both males and females were the straight pattern followed by the wavy and then the curved pattern. These results comparing to other studies based on the Thomas and Kotze classification showed some variations. It differed from Australian Aborigines and Caucasians, Rwandan, Saudi and Jordanian in all of whom the wavy shape was the most prevalent in males and females [11, 14-16].

A review of articles based on the Thomas and Kotze classification that were undertaken in the Indian subcontinent in the period between 2007 - 2013 showed that the wavy shape was the more common type of rugae in both males and females $[5,7,9$, 13, 17-24]. Considering these results, if we compare a group of dental casts of people from India with others from Sudan, we should regard the predominant rugal shapes in each cast. Further studies on this issue could help in improving forensic identification based on rugae shapes.

On the right side of the palate, the total number of straight rugae was more common in females than in males, whilst the wavy shape was significantly more common in males than females. These observations did not agree with the Rwandan sample that showed that the right side of the palate had a greater number of straight rugae in males than in females [16]. While on the left side of the palate, the curved shape of rugae were more prevalent in males than in females which conflicted with the Rwandan study in which the straight shape was more common in males than females [16]. Although the anatomy of the human body is always regarded to be symmetrical, the human palate is not. The right and the left side of the palate may have the same size but the rugae preva- 
Table 6. Distribution of different rugae shapes in males and females.

\begin{tabular}{|c|c|c|c|c|c|c|}
\hline & Gender & $\mathbf{N}$ & Rugae number & Mean & SD & P-value \\
\hline \multirow{2}{*}{ Straight } & Male & 50 & 126 & 2.52 & 1.7 & \multirow{2}{*}{$0.014^{*}$} \\
\hline & Female & 50 & 175 & 3.5 & 2.19 & \\
\hline \multirow{2}{*}{ Circular } & Male & 50 & 4 & 0.27 & 0.27 & \multirow{2}{*}{$0.043^{*}$} \\
\hline & Female & 50 & 12 & 0.48 & 0.48 & \\
\hline \multirow{2}{*}{ Curved } & Male & 50 & 123 & 2.46 & 1.68 & \multirow{2}{*}{0.08} \\
\hline & Female & 50 & 94 & 1.88 & 1.59 & \\
\hline \multirow{2}{*}{ Wavy } & Male & 50 & 159 & 3.18 & 1.77 & \multirow{2}{*}{$0.04^{*}$} \\
\hline & Female & 50 & 125 & 2.5 & 1.49 & \\
\hline \multirow{2}{*}{ Diverging unification } & Male & 50 & 56 & 1.12 & 1.06 & \multirow{2}{*}{$0.006^{*}$} \\
\hline & Female & 50 & 89 & 1.78 & 1.29 & \\
\hline \multirow{2}{*}{ Converging unification } & Male & 50 & 20 & 0.4 & 0.7 & \multirow{2}{*}{0.086} \\
\hline & Female & 50 & 33 & 0.66 & 0.79 & \\
\hline \multirow{2}{*}{ Unspecified } & Male & 50 & 6 & 0.12 & 0.48 & \multirow{2}{*}{0.804} \\
\hline & Female & 50 & 5 & 0.1 & 0.3 & \\
\hline
\end{tabular}

lence, rugae length and rugae shapes are different. This may be an assisted tool for identification by using the sides of the palate to distinguish between males and females from the same area or nationality. Showing a significant difference in the males and females with regard to the number, shape and length of palatal rugae might follow some studies which reported sex dimorphism $[12,14,18,22,24]$. This study showed individuality and uniqueness of the palatal rugae which were similar to some previous studies $[3,14,25]$. There were no identical patterns or even bilateral symmetry between the two sides of the palate noticed in any of the plaster casts. This valuable characteristic of the palatal rugae can be used as an aid in forensic identification.

\section{Conclusion}

This Sudanese study had shown statistically significant differences between males and females in the number of rugae, length of rugae and shapes of rugae. Hence, the individuality and uniqueness of palatal rugae can be used as a tool for forensic dental identification, and possibly distinction between males and females. The Thomas and Kotze classification was suggested to be applicable for Sudanese population.

\section{References}

[1]. Filho I, Sales-Peres S, Sales-Peres A, Carvalho S (2009) Palatal rugae patterns as bio-indicators of identification in Forensic Dentistry. RFO 14(3): $227-233$.

[2]. Bansode S, Kulkarni M (2009) Importance of palatal rugae in individual identification. Journal of Forensic Dental Sciences 1(2): 77- 81.

[3]. Patil MS, Patil SB, Acharya AB (2008) Palatal rugae and their significance in clinical dentistry, a review of literature. JADA 139(11): 1471 - 1478.

[4]. Limson KS, Julian R (2004) Computerized recording of palatal rugae pattern and evaluation of its application in forensic identification. J Forensic Odontostomatol 22(1): 1- 4.

[5]. Nayak P, Acharya A, Padmini AT, Kaveri H (2007) Difference in palatal rugae shape in two populations. Archive of Oral Biology 52(10): 977 - 982.

[6]. Indira AP, Gupta M, David M (2012) Palatal rugae pattern for establishing individuality. Journal of Forensic Dental Science 4(1): $2-5$.

[7]. Rajan VP, John JB, Stalin A, Priya G, Abuthagir AK (2013) Morphology of palatal rugae patterns among 5-15 years old children. Journal of Pharmacy \& Bioallied Sciences 5(1): 43-47.

[8]. Eboh D (2012) Palatal rugae patterns of Urhobos in Abraka, South-Southern Nigeria. Int. J. Morpholo 30(2): $709-713$
[9]. Surekha R, Anila K, Reddy VS; Hunasgi S, Ravikumar S, Ramesh N (2012) Assessment of palatal rugae patterns in Manipuri and Kerala population. Journal of Forensic Dental Sciences 4(2): 93-96.

[10]. Dohke M, Osato S (1994) Morphological study of the palatal rugae in Japanese. Bilateral differences in the regression evaluation of the palatal rugae. Jap J Oral Biol 36(2): 125 - 140 .

[11]. Mustafa AG, Allouh M, Tarawneh I, Alrbata R (2013) Morphometric analysis of palatal rugae among Jordanians: further evidence of worldwide palatal rugae individuality. Aust J Forensic Sci 46(1): 53-63.

[12]. Gondivkar SM , Patel S, Gadbail AR, Gaikwad RN, Chole R, et al., (2011) Morphological study of the palatal rugae in Western Indian population. Journal of Forensic and Legal Medicine 18(7): 310 - 312.

[13]. Bharath S, Kumar G, Dhanapal R, Sarswathi TR (2011) Sex determination by discriminant function analysis of palatal rugae from a population of coastal Andhra. Journal of Forensic Dental Science 3(2): 58-62.

[14]. Kapali S, Townsend G, Richards L, Parish T (1997) Palatal rugae patterns in Australian Aborigines and Caucasians. Australian Dental Journal 42(2): $129-133$.

[15]. Fahmi FM, Al-Shamrani SM, Talic YF (2001) Rugae pattern in a Saudi population sample of males and Female. Saudi Dental Journal 13(2): 92 -95 .

[16]. Goyal S, Goyal S (2013) Study of palatal rugae pattern of Rwandan patients attending the dental department at King Faisal Hospital, Kigali, Rwanda. Rwanda Medical Journal 70(1): $19-25$.

[17]. Paliwal A, Wanjari S, Parwani R (2010) Palatal rugoscopy: Establishing identity. Journal of Forensic Dental Sciences 2(1): 27 - 31.

[18]. Saraf A, Bedia S, Indukar A, Degwekar S, Bhowate R (2011) Rugae patterns as an adjunct to sex differentiation in forensic identification. J. Forensic Odontostomatology 29(1): $14-19$.

[19]. Sharma P, saxena S, Rathod V (2009) Comparative reliability of cheiloscopy and palatoscopy in human identification. Indian J Dent Res 20(4): $453-457$.

[20]. Shanmugam S, Anuthama K, Shaikh H, Murali K, Suresan V, et al., (2012) Palatal rugae in population differentiation between South and North Indians: A discriminate function analysis. Journal of Forensic Dental Sciences 4(2): $75-79$

[21]. Sumathi MK, Balaji N, Vezhavendhan N, Sathish KG, Shanthi V (2011) Palatoscopy among Pondicherry population. Journal of Scientific Dentistry 1(1): $16-18$

[22]. Kotrashetti V, Hollikatti K, Mallapur M, Hallikeremath S, Kale A (2011) Determination of palatal rugae patterns among two ethnic population of India by logistic regression analysis. Journal of Forensic and Legal Medicine 18(8): $360-365$.

[23]. Shetty M, Premalatha K (2011) Study of Palatal Rugae Pattern among the student population in Mangalore. J Indian Acad Forensic Med 33(2): 112 -115 .

[24]. Shetty SK, Kalia S, Patil K, Mahima VG (2005) Palatal rugae pattern in Mysorean and Tibetan population. Ind J Den Res 16(2): 51 - 55 .

[25]. Thomas CJ, KotzeT.J.v.W, Van der Merwe CA (1987) An improved statistical method for the racial classification of man by means of palatal rugae. Arch Oral Biol 32(4): 315 - 317 